Article

\title{
Investigation of R290 Flow Boiling Heat Transfer and Exergy Loss in a Double-Concentric Pipe Based on CFD
}

\author{
Jinfeng Wang ${ }^{1,2,3,4, *}$, Shenglin Zhu ${ }^{1}$ and Jing Xie ${ }^{1,2,3,4, *(D)}$ \\ 1 College of Food Science and Technology, Shanghai Ocean University, Shanghai 201306, China; \\ m190300696@st.shou.edu.cn \\ 2 Shanghai Cold Chain Equipment Performance and Energy Saving Evaluation Professional Technical Service Platform, \\ Shanghai 201306, China \\ 3 Shanghai Aquatic Product Processing and Storage Engineering Research Center, Shanghai 201306, China \\ 4 National Experimental Teaching Demonstration Center of Food Science and Engineering, Shanghai Ocean University, \\ Shanghai 201306, China \\ * Correspondence: jfwang@shou.edu.cn (J.W.); jxie@shou.edu.cn (J.X.)
}

Citation: Wang, J.; Zhu, S.; Xie, J. Investigation of R290 Flow Boiling Heat Transfer and Exergy Loss in a Double-Concentric Pipe Based on CFD. Energies 2021, 14, 7121. https://doi.org/10.3390/en14217121

\section{Academic Editors:}

Hamidreza Sadeghifar and Dmitry Eskin

Received: 30 August 2021

Accepted: 22 October 2021

Published: 1 November 2021

Publisher's Note: MDPI stays neutral with regard to jurisdictional claims in published maps and institutional affiliations.

Copyright: (c) 2021 by the authors. Licensee MDPI, Basel, Switzerland. This article is an open access article distributed under the terms and conditions of the Creative Commons Attribution (CC BY) license (https:/ / creativecommons.org/licenses/by/ $4.0 /)$.

\begin{abstract}
In this paper, the impact of different factors on the flow boiling of R290 and R22 in doubleconcentric pipes are investigated through CFD numerical simulations. The numerical studies are performed by changing the inner tube diameter in the range of 3 to $7 \mathrm{~mm}$, the refrigerant velocity between 1 and $5 \mathrm{~m} / \mathrm{s}$, the water velocity between 1 and $10 \mathrm{~m} / \mathrm{s}$ and the saturation temperature in the range of 276 to $283 \mathrm{~K}$. The heat transfer coefficient (HTC), pressure drop and exergy destruction of R290 are determined. The results show that HTC, pressure drop and exergy destruction are significantly impacted by the pipe diameter and the refrigerant velocity, but slightly impacted by water velocity and saturation temperature. Moreover, the exergy loss and pressure drop of R290 are $11.8-13.3 \%$ and $4.3-10.2 \%$ lower than those of R22. R290 has a lower energy loss than R22 in the evaporation process in the double-concentric pipe. However, the HTC of R290 is 57.3-59.7\% lower than that of R22. The HTC of R290 can be optimized by increasing the pipe diameter or the R290 velocity.
\end{abstract}

Keywords: R290; flow boiling; numerical simulation; pressure drop; exergy loss

\section{Introduction}

R22 is widely used in refrigeration systems. However, R22 will be completely banned in 2030 because it has high Global Warming Potential (GWP) and Ozone Depletion Potential (ODP) [1]. The replacement of synthetic refrigerants with natural refrigerants is an international research hotspot. R290 (propane), as a natural refrigerant, has the advantages of low price, similar thermodynamic properties to R22, ODP of 0 and GWP of less than 3 [2].

The impacts of both thermal and mass fluxes and saturation temperature have been researched with respect to the heat transfer characteristics of the R290 flow boiling in a tube. Chien [3] examined the impact of thermal and mass fluxes with respect to the HTC of R290 flow boiling in a microchannel with a diameter of $1.5 \mathrm{~mm}$. It was discovered that the HTC of R290 is proportional to the increase in thermal flux. Oliveira et al. [4] experimentally investigated the local HTC of R290 in a circular tube with a diameter of $1 \mathrm{~mm}$, and concluded that the HTC is mainly determined by thermal and mass fluxes. Jiong and Pamitran et al. [5,6] studied the impact of mass flux and heat flux on the HTC of R290 in smooth tubes with diameters of $0.5,1.5$ and $3.0 \mathrm{~mm}$. They found that the mass flux has a significant impact with respect to the HTC at the high quality region and thermal flux has a significant impact with respect to the HTC at the low quality region. Maqhbool et al. [7] explored the impact of mass flux, thermal flow density, saturation temperature with respect to the pressure drop and HTC of R290 in a smooth tube with a diameter of $1.7 \mathrm{~mm}$, and found a slight impact of mass flux on the HTC. Lillo et al. [8] studied HTC and pressure 
drop of R290 flow boiling in a circular tube with a diameter of $6 \mathrm{~mm}$, and reported that the impact of mass and thermal fluxes and saturation temperature with respect to the HTC and the pressure drop. Lee et al. [9] researched heat transfer characteristics and pressure gradients of R290 during an evaporating process inside a horizontal double-concentric pipe whose outer and inner dimeters were $12.70 \mathrm{~mm}$ and $9.52 \mathrm{~mm}$, respectively. It was observed that the average HTC is improved with the increase of mass flux. Mikielewicz et al. [10] amended the model which predicted the refrigerants flow boiling by using a large amount of experimental data. Prior works were devoted to the research of R290 flow boiling in the tubes. Fewer studies have been conducted on the exergy loss of R290 flow boiling in tubes.

The exergy destruction is proportional to the increase of useful work consumed, and the reduction of exergy losses can increase the efficiency of the system [11]. Sheikholeslami [12] experimentally investigated exergy destruction of nano-refrigerants during the condensation process in a horizontal tube, and found that exergy destruction decreased with increasing vapor quality and mass flow rate of nanofluid. Abu-Hamde [13] investigated the impact of the fin coil winding insert on exergy loss of the circular tube, and obtained the optimum and critical value for all operational and geometric variables. Etghani [14] researched the influence of the operating variables and geometric parameters on exergy destruction of a heat exchanger with shell and helical tubes, and revealed that exergy loss is significantly influenced by the diameters of the tubes and the cold flow rate. Furthermore, the optimum geometric of the heat exchanger with shell and helical tube was gained. Exergy loss analysis is one of the most powerful tools to obtain the optimal operating conditions for the system.

Therefore, while the state of experimental and simulation studies on the flow boiling of R290 is fairly widespread, there seems to be scarcity of data on the analysis of exergy loss analysis for the R290 flow boiling in smooth tubes and comparison with R22. The purpose of this article is to expand the data on R290 flow boiling for smooth tubes by supplying data about the HTCs, pressure drops and exergy loss of R290. They were determined at tube diameters ranging from 3 to $7 \mathrm{~mm}$, refrigerant velocity of between 1 and $5 \mathrm{~m} / \mathrm{s}$, water velocity of between 1 and $10 \mathrm{~m} / \mathrm{s}$ and saturation temperatures ranging from 276 to $283 \mathrm{~K}$.

\section{Numerical Model}

The double-concentric pipe consists of an internal and an external tube. It is shown in Figure 1. The refrigerant and water flow in the internal and external tubes, respectively. The effects of tube diameter, refrigerant velocity, water velocity and saturation temperature are investigated. Table 1 shows the internal and external tube dimensions.

Table 1. The dimensions of the double-concentric pipe.

\begin{tabular}{cccc}
\hline \multicolumn{1}{c}{ Tube } & Wall Thickness $\mathbf{( m m )}$ & $\mathbf{L} \mathbf{( m m})$ & $\left.\mathbf{D}_{\mathbf{o}} / \mathbf{D}_{\mathbf{i}} \mathbf{( m m}\right)$ \\
\hline External tube/internal tube & 0.21 & $2000 / 2000$ & $9.42 / 3$ \\
External tube/internal tube & 0.21 & $2000 / 2000$ & $10.42 / 4$ \\
External tube/internal tube & 0.21 & $2000 / 2000$ & $11.42 / 5$ \\
External tube/internal tube & 0.21 & $2000 / 2000$ & $12.42 / 6$ \\
External tube/internal tube & 0.21 & $2000 / 2000$ & $13.42 / 7$ \\
\hline
\end{tabular}

\subsection{Numerical Procedure}

The numerical simulation of R290 flow boiling in the double tube is completed using ANSYS 19.0. Geometric modeling is established in DesignModeler, meshing is completed in Mesh, and finally algorithm setup and calculations are performed in Fluent. The Mixture multiphase flow model and $\mathrm{k}-\varepsilon$ turbulence model are selected. 


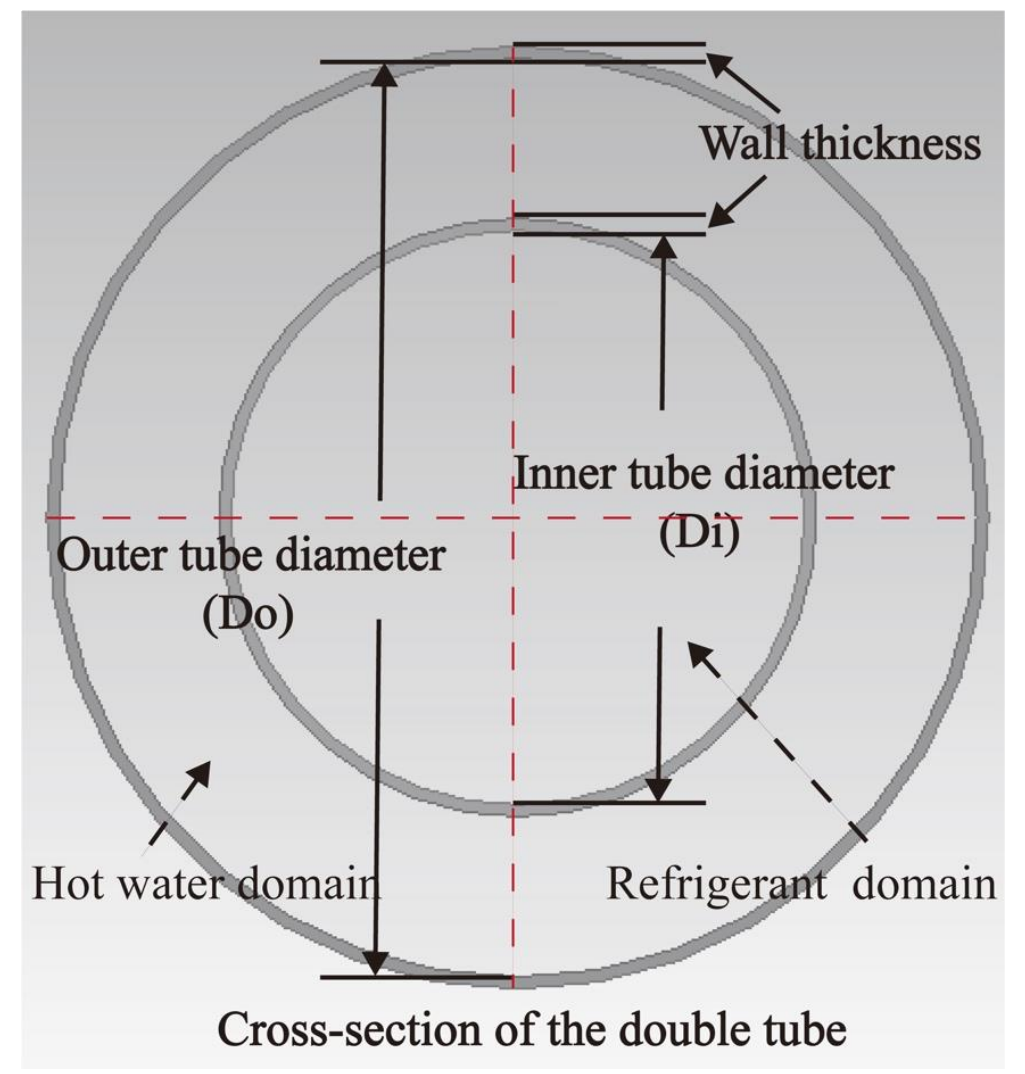

Figure 1. The cross-section of the double-concentric pipe.

\subsection{Governing Equations}

The continuity and momentum equations are taken to evaluate the velocity the velocity domain in the numerical simulation of fluid flow. The energy equation is adopted to evaluate the temperature field.

The continuity, momentum and energy equations of the mixed phase and the volume fraction of the second phase are included in the Mixture Model.

Continuity equation:

$$
\begin{gathered}
\frac{\partial\left(\rho_{m}\right)}{\partial t}+\nabla \cdot\left(\rho_{m} \vec{v}_{m}\right)=0 \\
\vec{v}_{m}=\frac{\sum_{k=1}^{n} \alpha_{k} \rho_{k} \vec{v}_{k}}{\rho_{m}} \\
\rho_{m}=\sum_{k=1}^{n} \alpha_{k} \rho_{k}
\end{gathered}
$$

where $\vec{v}_{m}$ is the mass-average velocity, $\rho_{m}$ the mixed density, $\alpha_{k}$ is the $k$ th phase volume fraction, $\rho_{k}$ is the $k$ th phase density, and $\vec{v}_{k}$ is the $k$ th phase velocity.

Momentum equation:

$$
\begin{aligned}
\frac{\partial\left(\rho_{m} \vec{v}_{m}\right)}{\partial t}+ & \nabla \cdot\left(\rho_{m} \vec{v}_{m} \vec{v}_{m}\right)=-\nabla \cdot \rho+\nabla \cdot\left[\mu_{m}\left(\nabla \cdot \vec{v}_{m}+\nabla \cdot \vec{v}_{m}^{T}\right)\right] \\
& +\rho_{m} \vec{g}+\vec{F}-\nabla \cdot\left(\sum_{k=1}^{n} \alpha_{k} \rho_{k} \vec{v}_{d r, k} \vec{v}_{d r, k}\right)
\end{aligned}
$$

where $n$ is the amount of phase, $\vec{F}$ is the bulk force, $\mu_{m}$ is the mixed viscosity.

$$
\mu_{m}=\sum_{k=1}^{n} \alpha_{k} \mu_{k}
$$


$\vec{v}_{d r, k}$ is the $k$ th phase drift velocity vector.

$$
\vec{v}_{d r, k}=\vec{v}_{k}-\vec{v}_{m}
$$

Energy equation:

$$
\frac{\partial\left(\sum_{k=1}^{n} \alpha_{k} \rho_{k} E_{k}\right)}{\partial t}+\nabla \cdot \sum_{k=1}^{n}\left(\alpha_{k} \vec{v}_{k}\left(\rho_{k} E_{k}+p\right)\right)=\nabla \cdot\left(k_{e f f} \nabla T-\sum_{k} \sum_{j} H_{j, k} \overrightarrow{J_{J \cdot k}}+\left(\overline{\overline{\tau_{e f f}}} \cdot \vec{v}\right)\right)+S_{h}
$$

where $H_{j . k}$ is the $k$ th phase enthalpy of species $j, \overrightarrow{J_{J . k}}$ is the $k$ th phase diffusive flux of species $j, S_{h}$ is the volumetric heat sources, $k_{e f f}$ is the effective conductivity calculated as:

$$
k_{e f f}=\sum \alpha_{k}\left(k_{k}+k_{t}\right)
$$

where $k_{t}$ is the turbulent thermal conductivity.

Second phase volume fraction equation:

$$
\frac{\partial\left(\alpha_{p} \rho_{p}\right)}{\partial t}+\nabla \cdot\left(\alpha_{p} \rho_{p} \vec{v}_{m}\right)=-\nabla \cdot\left(\alpha_{p} \rho_{p} \vec{v}_{d r, p}\right)+\sum_{q=1}^{n}\left(m_{q p}-m_{p q}\right)
$$

The secondary phase $(p)$ velocity with respect to the primary phase $(q)$ is defined as the relative velocity.

$$
\vec{v}_{d r, p}=\vec{v}_{q p}-\sum_{k=1}^{n} \frac{\alpha_{k} \rho_{k}}{\rho_{m}} \vec{v}_{q k}
$$

where $\vec{v}_{d r . p}$ is the $k$ th phase velocity with respect to the $q$ phase.

The $\overrightarrow{v_{q p}}$ is expressed by the following equation.

$$
\vec{v}_{q p}=\vec{v}_{p}-\vec{v}_{q}
$$

The turbulence model is chosen as the RNG model with standard near-wall treatment, which contains the following equations:

$$
\frac{\partial \rho(k)}{\partial t}+\frac{\partial\left(\rho k \mu_{i}\right)}{\partial x_{i}}=\frac{\partial\left[\alpha_{k} \mu_{e f f} \frac{\partial k}{\partial x_{j}}\right]}{\partial x_{j}}+G_{k}+G_{b}-\rho \epsilon-Y_{M}+S_{k}
$$

and

$$
\frac{\partial(\rho \varepsilon)}{\partial t}+\frac{\partial\left(\rho \varepsilon \mu_{i}\right)}{\partial x_{i}}=\frac{\partial\left[\alpha_{\varepsilon} \mu_{e f f} \frac{\partial \varepsilon}{\partial x_{i}}\right]}{\partial x_{i}}+C_{1 \varepsilon} \frac{\varepsilon}{k}\left(G_{k}+C_{3 \varepsilon} G_{b}\right)-C_{2 \varepsilon} \rho \frac{\varepsilon^{2}}{k}-R_{\varepsilon}+S_{\varepsilon}
$$

where $G_{k}$ is the turbulent kinetic energy that results from the average velocity gradient, $G_{b}$ is the turbulence kinetic energy that results from buoyancy, $Y_{M}$ is the overall dissipation rate contribution from fluctuating expansion in compressible turbulence, $k$ is turbulent pulsation kinetic energy, $\varepsilon$ is turbulent pulsation kinetic energy dissipation rate, $S_{k}$ and $S_{\varepsilon}$ are user-defined source terms, $C_{1}, C_{2}$ and $C_{3}$ are constant factor.

\subsection{Boundary Condition and Numerical Method}

(a) The velocity-inlet and pressure-outlet conditions are used in present simulation model.

(b) The inner pipe wall is set as the coupling boundary, and the outer pipe wall is set as adiabatic. Copper is the material of the tube wall.

(c) The viscosity, thermal conductivity, density, and specific heat of each phase of the fluid are constant, and the latent heat and surface tension of the fluid are also constant.

(d) The effect of surface tension is taken into account in the model, and the option "implicit body force" is activated in the Mixture Model. The liquid phase of R290 is 
set as the first phase, the gas phase of R290 is set as the second phase, and the water in the outer tube is set as the third phase in the Model.

(e) The governing equations are solved by steady-sated implicit format.

(f) This simulation algorithm is set up: COUPLE is chosen to be used for the pressurevelocity coupling and QUICK is chosen for the volume fraction equation. The firstorder upwind scheme is adopted for the energy, the volume and the turbulent kinetic energy equations.

(g) The convergence is achieved for energy up to $10^{-6}$ and for other variables (continuity, $\mathrm{x}$-velocity, y-velocity, z-velocity, k, epsilon, volume fraction-R290-vapor, volume fraction-water) up to $10^{-3}$.

\subsection{Grid Independence Check}

As shown in Figure 2, an unstructured hexahedral gird is used for numerical calculation to examine the numerical simulation results in relation to the number of elements, the value of HTCs is investigated, in 0.81-11.8 million elements. The impact of the number of elements with respect to the results can be ignored after 7.55 million elements, as shown in Figure 3. In addition, the numerical simulation results of 3.87 elements have $0.26 \%$ error compared with those of 7.55 million elements. Therefore, in order to reduce the computations, 3.87 million elements are chosen for numerical calculations.

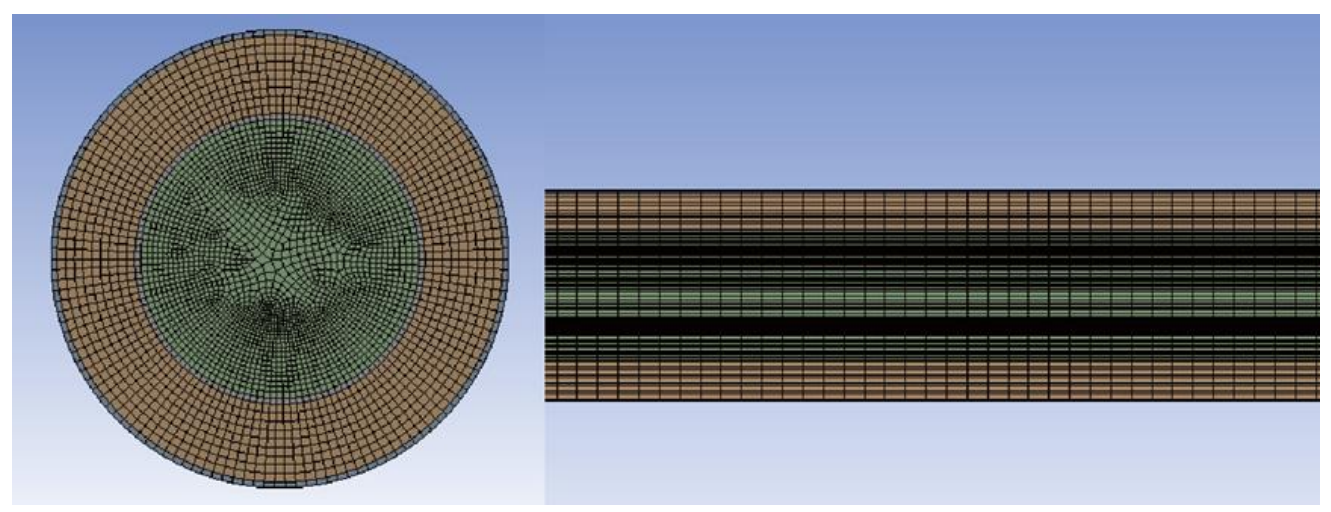

Figure 2. Grid system of the double-concentric pipe.

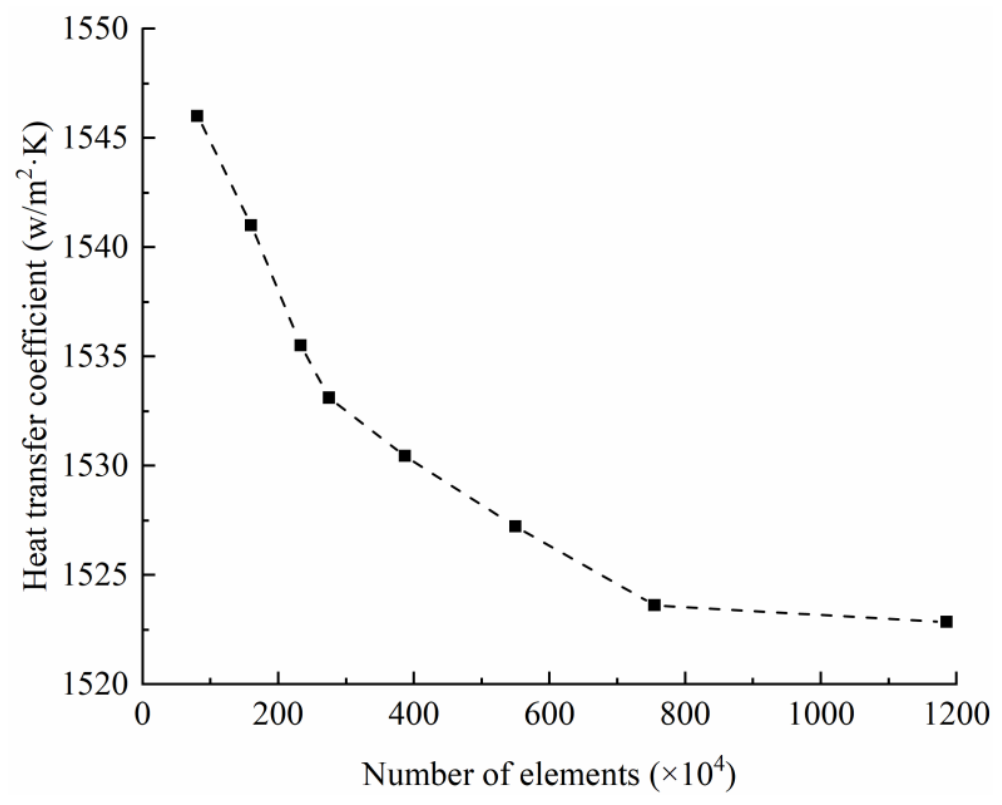

Figure 3. A study of the grid independence of HTC with different number of elements. 


\subsection{Model Verification}

Figure 4 is the validation of present study with empirical correlations. The 3.87 million elements are chosen for numerical calculations to verify the numerical simulation results by experimental results. Then, the results of CFD-based internal heat transfer coefficient is evaluated with empirical correlations. The length of the tube is kept $2000 \mathrm{~mm}$ and its diameter is $5 \mathrm{~mm}$. The water and refrigerant inlet temperature are kept at $320 \mathrm{~K}$ and $282 \mathrm{~K}$, respectively. The mass flow rate of refrigerant is changed from 0.04 to $0.2 \mathrm{~kg} / \mathrm{s}$. The HTC and pressure drop of the smooth tube are used as parameters to validate the model. A maximum deviation of $8.96 \%$ with Liu and Winterton's empirical equation [15] are observed for the heat transfer coefficient. A maximum deviation of $9.09 \%$ with $\mathrm{Xu} \&$ Fang empirical equation [16] are observed for pressure drop.

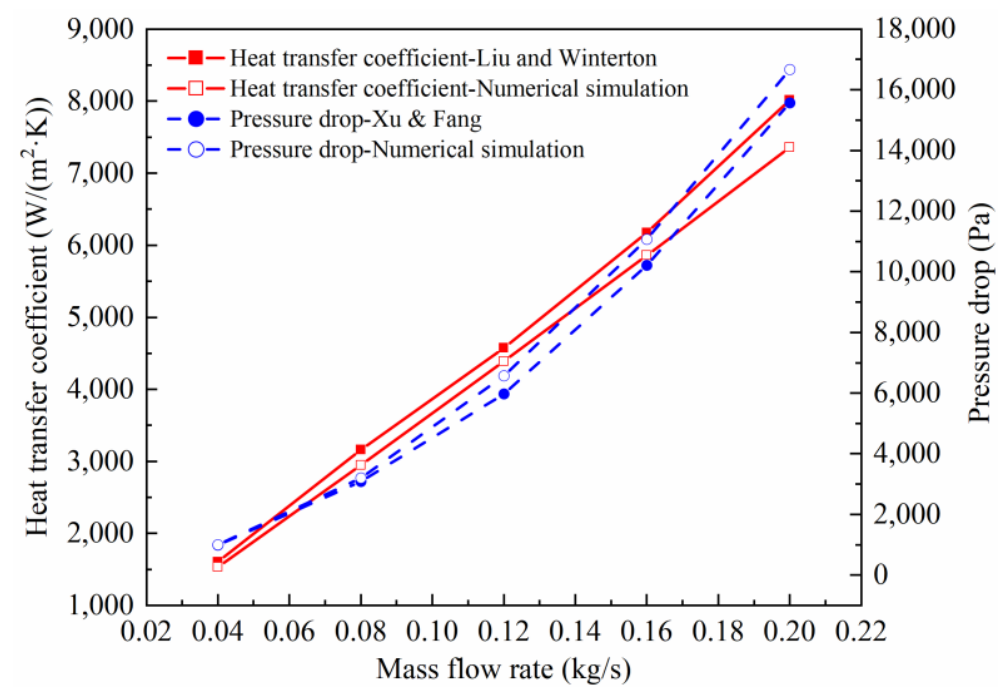

Figure 4. Validation of present study with empirical correlations.

Liu and Winterton empirical equation:

$$
H T C=\left[\left(E h_{2}\right)^{2}+\left(F h_{1}\right)^{2}\right]^{0.5}
$$

where the forced convection heat transfer enhancement factor is represented by $E$ and the suppression factor is represented by $F$. E $h_{2}$ is forced convection mechanism contribution and $\mathrm{Sh}_{1}$ indicates the contribution to the nucleate boiling mechanism. The $h_{2}$ is calculated by Equation (16) and the $\mathrm{h}_{1}$ is calculated by Equation (17).

$$
h_{2}=0.023 R_{e}^{0.8} \operatorname{Pr}^{0.4} \frac{\lambda}{D_{i}}
$$

where $P_{r}$ is Prandtl number and Re is Reynolds number; $\lambda$ is liquid thermal conductivity; $D_{i}$ is the inner tube diameter.

$$
h_{1}=55 P_{f}^{0.12}\left(-\log _{10} P_{f}\right)^{-0.55} M^{-0.5} Q^{0.67}
$$

where $M$ is molecular weight and $Q$ is thermal flux. $P_{f}$ is reduced pressure (absolute pressure/critical pressure)

$$
E=\left[1+\operatorname{Pr}\left(\frac{\rho_{l}}{\rho_{v}}-1\right)\right]^{0.35}
$$

where $\rho_{l}$ and $\rho_{v}$ are liquid and vapor density, respectively. $\operatorname{Pr}$ is Prandtl number.

$$
F=\left(1+0.055 E^{0.1} R e^{0.16}\right)^{-1}
$$


where $v_{l}$ is the liquid velocity and $\mu_{l}$ is the liquid dynamic viscosity.

$\mathrm{Xu} \&$ Fang empirical equation:

$$
\begin{gathered}
\Delta \mathrm{P}=\operatorname{Lf} \frac{m_{l}^{2}}{2 D_{i} \rho} \\
\mathrm{f}=0.25\left[\log \left(\frac{150.39}{R e^{0.98865}}-\frac{152.66}{R e}\right)\right]^{-2}
\end{gathered}
$$

where $\mathrm{L}$ and $D_{i}$ is the tube length and diameter, respectively. $m_{l}$ is the liquid mass flux, and $\rho_{l}$ is the liquid density.

\section{Calculation Method}

Exergy is defined as the maximum work that the system performs on the environment in the reversible process of achieving complete equilibrium with the environment. The reference environmental conditions must be assumed when calculating the exergy. The environmental reference temperature is $298 \mathrm{~K}$ in this paper.

The heat exchanger's exergy loss is separated into two categories: loss of temperature differential and friction pressure drop. These irreversible losses can be reduced by some measures $[17,18]$. The exergy analysis only considers the irreversibility of heat transfer and does not consider the irreversibility of friction in this article.

The total exergy $(E x)$ of the system can be expressed as [19]:

$$
E x=E x^{P H}+E x^{K N}+E x^{P T}+E x^{C H}
$$

where $E x^{P H}$ is physical exergy, $E x^{K N}$ is kinetic exergy, $E x^{P T}$ is potential exergy, and $E x^{C H}$ is chemical exergy.

Physical exergy accounts for the major part of the exergy of the heat exchange system. Therefore, chemical exergy, potential exergy and other exergies are ignored in this article. The calculated expression for the exergy balance of a stable open system is [20]:

$$
\sum \dot{E} \dot{x}_{\mathrm{i}}-\sum \dot{E} \dot{x}_{\mathrm{o}}+\sum \dot{E} \dot{x}_{\text {product }}=0
$$

The difference between the theoretical maximum work that the system can achieve and the actual work done is the work loss of the system.

$$
\dot{W}_{\text {lost }}=\dot{W}_{\text {max }}-\dot{W}_{\text {actual }}=\dot{E x}_{\text {loss }}
$$

The exergy loss is the work loss of the system. Therefore, the expression of the exergy loss of the steady-state open system is

$$
\dot{E x} x_{\text {loss }}=\sum \dot{m}_{i}\left(H_{i}-T_{e} s_{i}\right)-\sum \dot{m}_{o}\left(H_{o}-T_{e} s_{o}\right)+\sum \dot{Q}_{j}\left(1-\frac{T_{e}}{T_{j}}\right)-\dot{W}_{e v}
$$

where $\dot{Q}_{j}$ is the thermal transfer time rate that occurs at the $j$ th location on the control volume boundary, $T_{j}$ is the transient temperature there and $W_{e v}$ the work transfer time rate for work.

The expression for calculating the energy loss of the heat exchange system is:

$$
\dot{E} x_{\text {loss }}=\dot{m}_{c}\left(H_{c i}-H_{c o}\right)+\dot{m}_{h}\left(H_{h i}-H_{h o}\right)+T_{e}\left[\dot{m}_{c}\left(s_{c o}-s_{c i}\right)+\dot{m}_{h}\left(s_{h o}-s_{h i}\right)\right]
$$

If heat loss in the heat exchanger is assumed to be neglected, the hot fluid provides the same amount of heat as the cold fluid absorbs. Thus Equation (15) can be transformed as follows

$$
\dot{E x_{\text {loss }}}=T_{e}\left[\dot{m}_{c}\left(s_{c o}-s_{c i}\right)+\dot{m}_{h}\left(s_{h o}-s_{h i}\right)\right]
$$


The specific heat at constant pressure can be used to express the change in entropy of hot and cold fluids,

$$
s_{c o}-s_{c i}=C_{p c} \ln \left(T_{c o} / T_{C I}\right), s_{h o}-s_{h i}=C_{p h} \ln \left(T_{h o} / T_{h i}\right)
$$

and substitute Equation (28) into Equation (27),

$$
\dot{E} x_{\text {loss }}=T_{e}\left[\dot{m}_{h} C_{p h} \ln \left(T_{h o} / T_{h i}\right)+\dot{m}_{c} C_{p c} \ln \left(T_{c o} / T_{c i}\right)\right]
$$

The calculated expressions for the heat capacity of hot and cold fluids, and the ratio of heat capacity, are:

$$
\begin{gathered}
C_{h}=\dot{m}_{h} C_{p h}, C_{c}=\dot{m}_{c} C_{p c} \\
C_{r}=C_{\text {min }} / C_{\text {max }}
\end{gathered}
$$

Mood A. $\left(C_{\min }=C_{h}\right): m_{c} C_{p c}>m_{h} c_{p h}$. Mood B. $\left(C_{\min }=C_{c}\right): m_{c} C_{p c}<m_{h} C_{p h}$.

It is assumed that the heat capacity of the cold fluid (R290) is minimized, and the exergy loss can be calculated by Equation (32).

$$
\dot{E} x_{\text {loss }}=T_{e}\left[C_{\min } \ln \left(T_{h o} / T_{h i}\right)+C_{\max } \ln \left(T_{c o} / T_{c i}\right)\right]
$$

The temperature ratio of the hot and cold fluids and heat transfer efficiency $(\varepsilon)$ can be expressed as

$$
T_{r}=\frac{T_{h i}}{T_{c i}}, \varepsilon=\frac{Q}{Q_{\max }}=\frac{C_{\max }\left(T_{c o}-T_{c i}\right)}{C_{\min }\left(T_{h i}-T_{c i}\right)}=\frac{C_{\min }\left(T_{h i}-T_{h o}\right)}{C_{\min }\left(T_{h i}-T_{c i}\right)}
$$

By substituting Equation (23) into Equation (22), the exergy loss can be expressed as

$$
\dot{E} x_{\text {loss }}=T_{e}\left[C_{\min } \ln \left(1-\varepsilon C_{r}\left(1-\frac{1}{T_{r}}\right)\right)+C_{\max } \ln \left(1+\varepsilon\left(T_{r}-1\right)\right)\right]
$$

\section{Results and Discussion}

\subsection{HTC Analysis}

\subsubsection{The Impact of Diameter on HTC}

To investigate the impact of the tube diameter on HTC. The saturation temperature is kept $283 \mathrm{~K}$ and the water velocity is kept at $5 \mathrm{~m} / \mathrm{s}$. The trend of the HTC on the refrigerant side with the inner tube diameter for five different R290 velocities are shown in Figure 5a. The HTC of the R290 side increases with the increase of the inner tube diameter. The volume fraction of R290 vapor for different pipe diameters at the internal tube wall surface in the direction of the tube length are shown in Figure 5b. For smaller tube diameters, the volume fraction of R290 vapor generated is larger on the inner tube surface. A stable vapor film layer is formed. The vapor film layer prevents heat transfer. Therefore, the R290 side HTC increased with increasing inner tube diameter. When R290 velocity is $1 \mathrm{~m} / \mathrm{s}$ and $5 \mathrm{~m} / \mathrm{s}$, the HTC increases by $43.4 \%$ and $32.2 \%$, respectively. Figure $5 \mathrm{c}$ shows the HTC of R290 and R22 for various tube diameters at a refrigerant velocity of $1 \mathrm{~m} / \mathrm{s}$. The HTC of R290 is 12.1-12\% lower than that of R22 at different pipe diameters. It can be found that the HTC of R290 are 3.4\%, 13.9\%, 21.0\% and 26.1\% higher at the pipe diameter of $4 \mathrm{~mm}, 5 \mathrm{~mm}$, $6 \mathrm{~mm}$ and $7 \mathrm{~mm}$ than that of R22 at the pipe diameter of $3 \mathrm{~mm}$, respectively. Therefore, the HTC of R290 can be improved by increasing the tube diameter. 

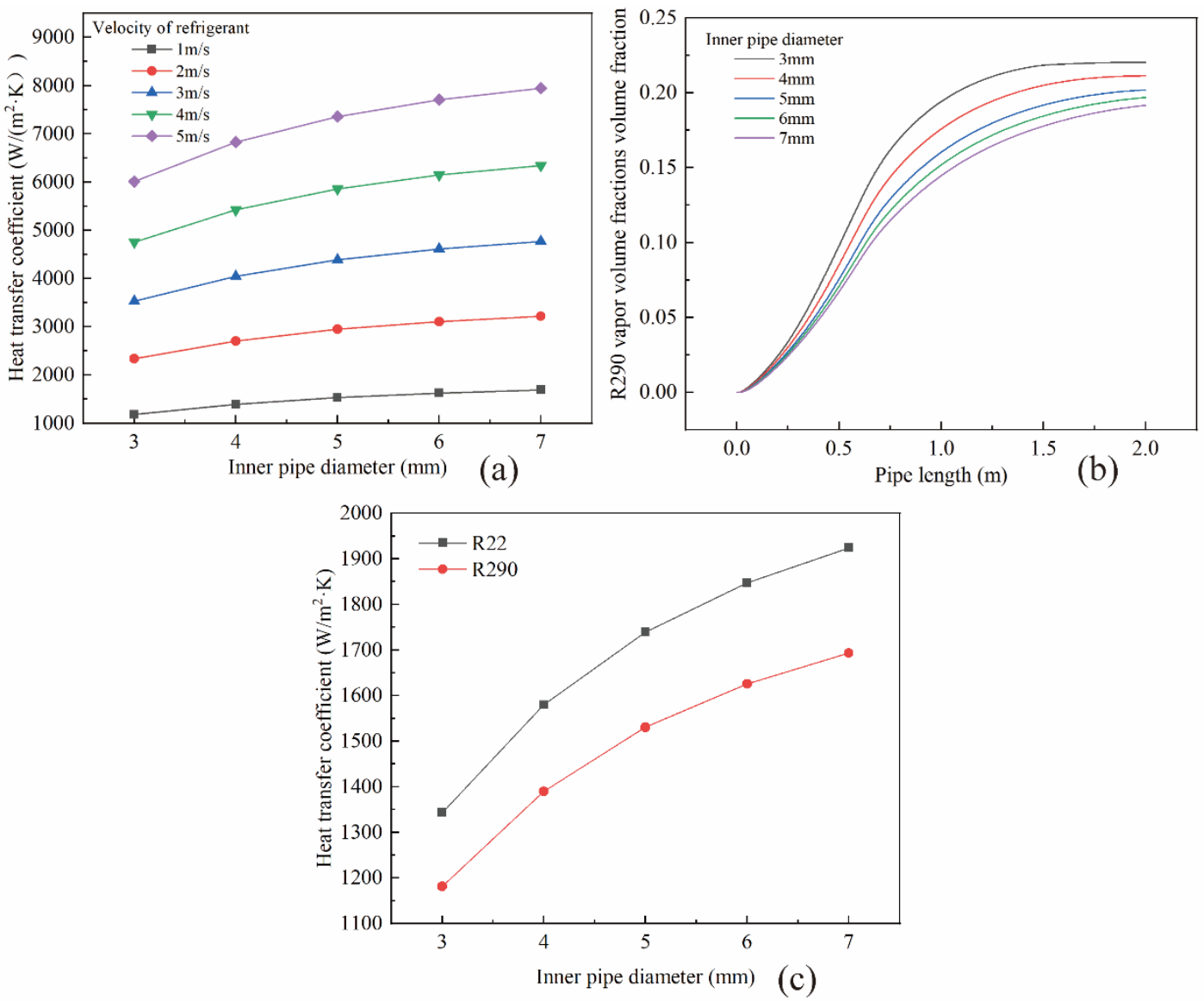

Figure 5. The impact of (a) inner pipe diameter on HTC, (b) R290 volume fraction at the inner tube wall surface and (c) HTC for R22 and R290 at different pipe diameters.

\subsubsection{The Impact of Refrigerant Velocity on HTC}

To investigate the impact of refrigerant velocity on HTC, the saturation temperature is kept $283 \mathrm{~K}$ and the water velocity is kept $5 \mathrm{~m} / \mathrm{s}$. The trend of R290 side HTC with R290 velocity for different pipe diameters is presented in Figure 6a. The HTC on the R290 side is proportional to the refrigerant velocity, and the velocity of R290 has a significant impact on the HTC. The volume fractions of R290 vapor for different R290 velocities at the internal pipe wall surface in the direction of the tube length are shown in Figure $6 \mathrm{~b}$. For the smaller R290 velocity, the volume fraction of R290 vapor generated is larger at the internal pipe wall surface, leading to the formation of a stable vapor film layer. The vapor film prevents heat transfer, resulting in a lower HTC at the smaller R290 velocity. The flow becomes more intense with the increase of R290 velocity, resulting in enhanced heat transfer. R290 side HTC enhances significantly with increasing refrigerant velocity [21]. Figure $6 \mathrm{c}$ shows that the HTC of R290 is $25.7 \%$ lower than that of R22 at a refrigerant velocity of $1 \mathrm{~m} / \mathrm{s}$ and $13.3 \%$ lower than that of R22 at refrigerant velocities of 2 to $5 \mathrm{~m} / \mathrm{s}$. As shown in Figure $6 \mathrm{c}$, it can be found that the R290 HTC is more than the R22 when the R290 velocity is larger than the R22. The HTC of R290 at a velocity of $2 \mathrm{~m} / \mathrm{s}$ is $43.2 \%$ higher than that of R22 at a velocity of $1 \mathrm{~m} / \mathrm{s}$. The HTC of R290 at a velocity of $3 \mathrm{~m} / \mathrm{s}$ is $30.6 \%$ higher than that of R22 at a velocity of $2 \mathrm{~m} / \mathrm{s}$. The HTC of R290 at a velocity of $4 \mathrm{~m} / \mathrm{s}$ is $16.5 \%$ higher than that of R22 at a velocity of $3 \mathrm{~m} / \mathrm{s}$. The HTC of R290 at a velocity of $5 \mathrm{~m} / \mathrm{s}$ is $9.2 \%$ higher than that of R22 at a velocity of $4 \mathrm{~m} / \mathrm{s}$. Therefore, the HTC of R290 can be enhanced by increasing the R290 velocity. 

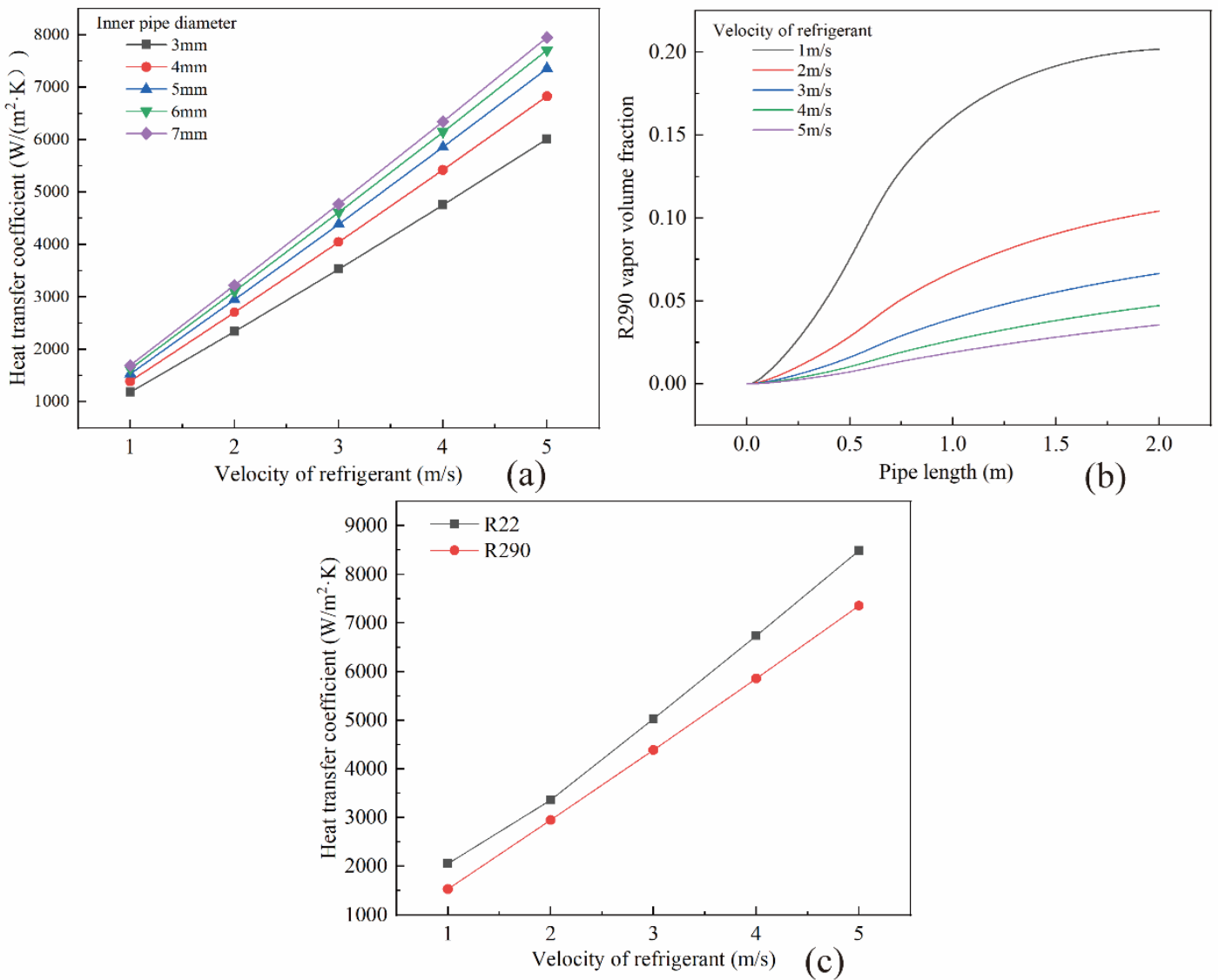

Figure 6. The impact of (a) refrigerant velocity on HTC, (b) R290 volume fraction the inner tube wall surface and HTC for R22 and (c) R290 at different refrigerant velocities.

\subsubsection{The impact of water velocity on HTC}

To investigate the impact of water velocity on HTC, the saturation temperature is kept $283 \mathrm{~K}$ and the tube diameter is kept $5 \mathrm{~mm}$. The trend of HTC on the R290 side with different water velocities for five different R290 velocities are shown in Figure 7a. The HTC on the R290 side tends to decrease when the water velocity increases. The increase of water velocity leads to a higher mass flow rate of water. Thereby the heat supply of outside tube increases. The volume fractions of R290 vapor for different water velocities at the internal tube wall surface in the direction of the tube length are shown in Figure $7 \mathrm{~b}$. A stable vapor film layer is formed. The vapor film layer has large thermal resistance and hampers heat transfer. Therefore, the R290 side HTC decreases with the increase of water velocity. Figure 7c shows that the HTC of R290 is 13\% lower than that of R22 at the water velocity of $1 \mathrm{~m} / \mathrm{s}$ and $11.8 \%$ lower than that of R22 when the water velocity is $10 \mathrm{~m} / \mathrm{s}$.

\subsubsection{The Impact of Saturation Temperature on HTC}

To research the impact of saturation temperature with respect to HTC, the water velocity is kept at $5 \mathrm{~m} / \mathrm{s}$ and the tube diameter is kept at $5 \mathrm{~mm}$. The trends of HTC of R290 side with different saturation temperatures for five different R290 velocities are shown in Figure $8 \mathrm{a}$. The HTC of the refrigerant side tends to decrease with the range of about $2-21.6 \%$ when the saturation temperature increases. The impact of the saturation temperature on the R290 side HTC is more significant at the larger R290 velocity. 


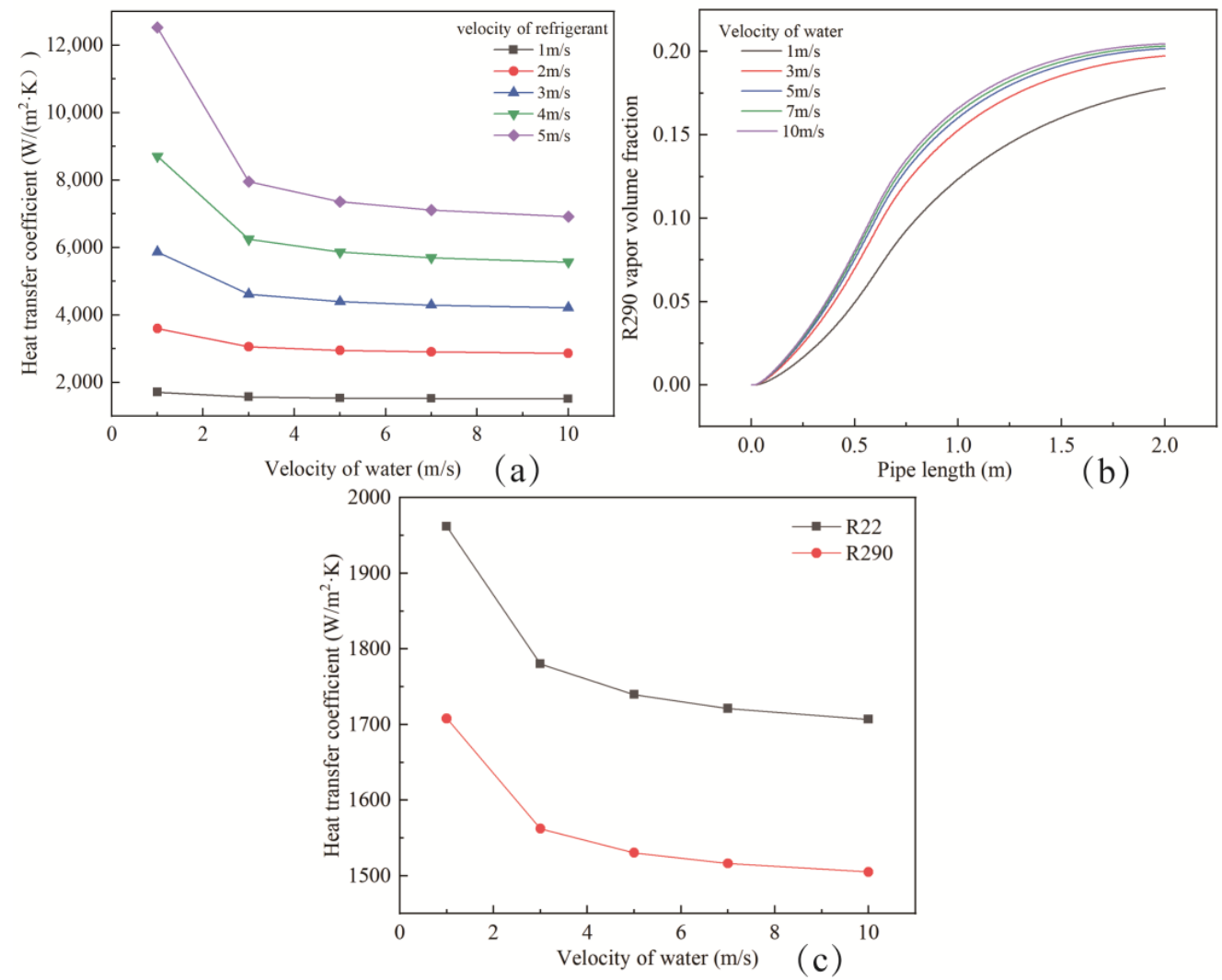

Figure 7. The impact of (a) velocity of water on HTC, (b) R290 volume fraction at the innertube wall surface and (c) HTC for R22 and R290 at different water velocities.
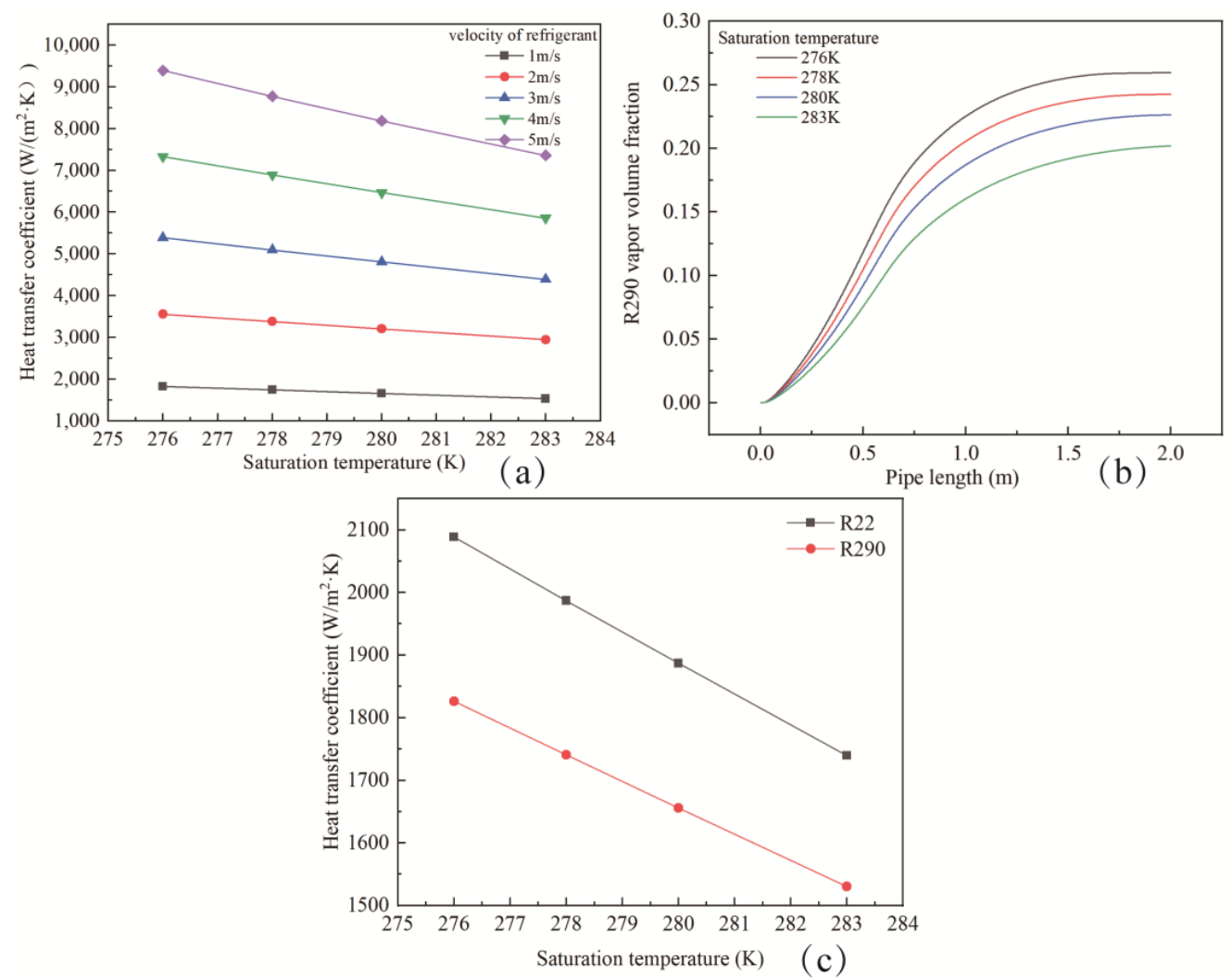

Figure 8. The impact of (a) saturation temperature on HTC, (b) R290 volume fraction at the inner tube wall surface and (c) HTC for R22 and R290 at different saturation temperatures. 
The generation and departure of the bubbles are critical during the evaporation of the refrigerant in the inner tube. The surface tension, the floatation of the fluid and the resistance of the fluid are the factors which affect the growth and detachment of bubbles. The surface tension decreases as the saturation temperature increases. The reduction of surface tension facilitates the generation of smaller diameter bubbles and to separate the bubbles from the wall. The saturation temperature has a more significant impact on the gas density than the liquid density. The floatation force of the fluid has a smaller effect on the bubbles. The viscosity of the liquid decreases as the saturation temperature increases. The influence of the liquid resistance on the bubbles is reduced. With increases in the saturation temperature, the thermal conductivity and the liquid density of R290 decreases, while the gas density increases, causing the average velocity of the vapor-liquid mixed phase to decrease and convective heat transfer to weaken. Flow boiling has approximately equal effects on heat transfer facilitation and suppression. The volume fractions of R290 vapor for different saturation temperatures at the inner pipe wall surface in the direction of the pipe length are shown in Figure 8b. Therefore, the trend of HTC on the refrigerant side with the change of saturation temperature is not significant [22]. Figure $8 \mathrm{c}$ reveals that the HTC of R290 is 12-12.6\% lower than that of R22. The HTC of R290 at a saturation temperature of $276 \mathrm{~K}$ is $4.99 \%$ larger than that of R22 at a saturation temperature of $283 \mathrm{~K}$. The HTC of $\mathrm{R} 290$ at a saturation temperature of $278 \mathrm{~K}$ is $0.1 \%$ larger than that of $\mathrm{R} 22$ at a saturation temperature of $283 \mathrm{~K}$. Therefore, the HTC of R290 can be brought to the HTC of R22 by reducing the saturation temperature of R290.

\subsection{Pressure Drop Analyses}

The pressure drop of two-phase flow is grouped into four components: frictional resistance pressure drop, local resistance pressure drop, repositioning pressure drop and acceleration pressure drop. The frictional resistance pressure drop is generated by the friction between the refrigerant and the pipe internal wall and the local resistance pressure drop is generated by the refrigerant flowing through various pipe fittings inside the pipe. The repositioning pressure drop is generated by the gravitational potential energy of the refrigerant in different positions inside the pipe and the acceleration pressure drop is generated by the different density and speed of the vapor-liquid two phase in the tube. In this paper, local resistance pressure drop and repositioning pressure drop are not considered due to the simulated pipe being a horizontal smooth pipe. The frictional resistance pressure drop account for the largest proportion.

\subsubsection{The Impact of Diameter on Pressure Drop}

To research the impact of the tube diameter with respect to pressure drop, the saturation temperature is kept at $283 \mathrm{~K}$ and the water velocity is kept at $5 \mathrm{~m} / \mathrm{s}$. The trend of the pressure drop with the inner tube diameter for five different R290 velocities is presented in Figure 9a. The pressure drop in the internal tube decreases as the tube diameter increases. As seen in Figure $9 b$, the shear stress on the internal pipe wall surface gradually decreases with increasing the tube diameter, causing the velocity gradient and the disturbance of the inner tube wall surface to decrease. It leads to the decrease of the friction force between the refrigerant and the internal pipe wall surface. Therefore, the frictional resistance pressure drop between the refrigerant and the internal pipe wall surface decreases. The volume fraction of refrigerant gas decreased continuously with the increase of tube diameter, and the acceleration pressure drop that is generated by the different density and velocity of gas-liquid phase also decreases [23]. Figure 9c reveals that the pressure drops of R290 is $58.1-58.3 \%$ lower than that of R22 for different inner tube diameters. The difference in pressure drop between R290 and R22 is slight at various tube diameters. 

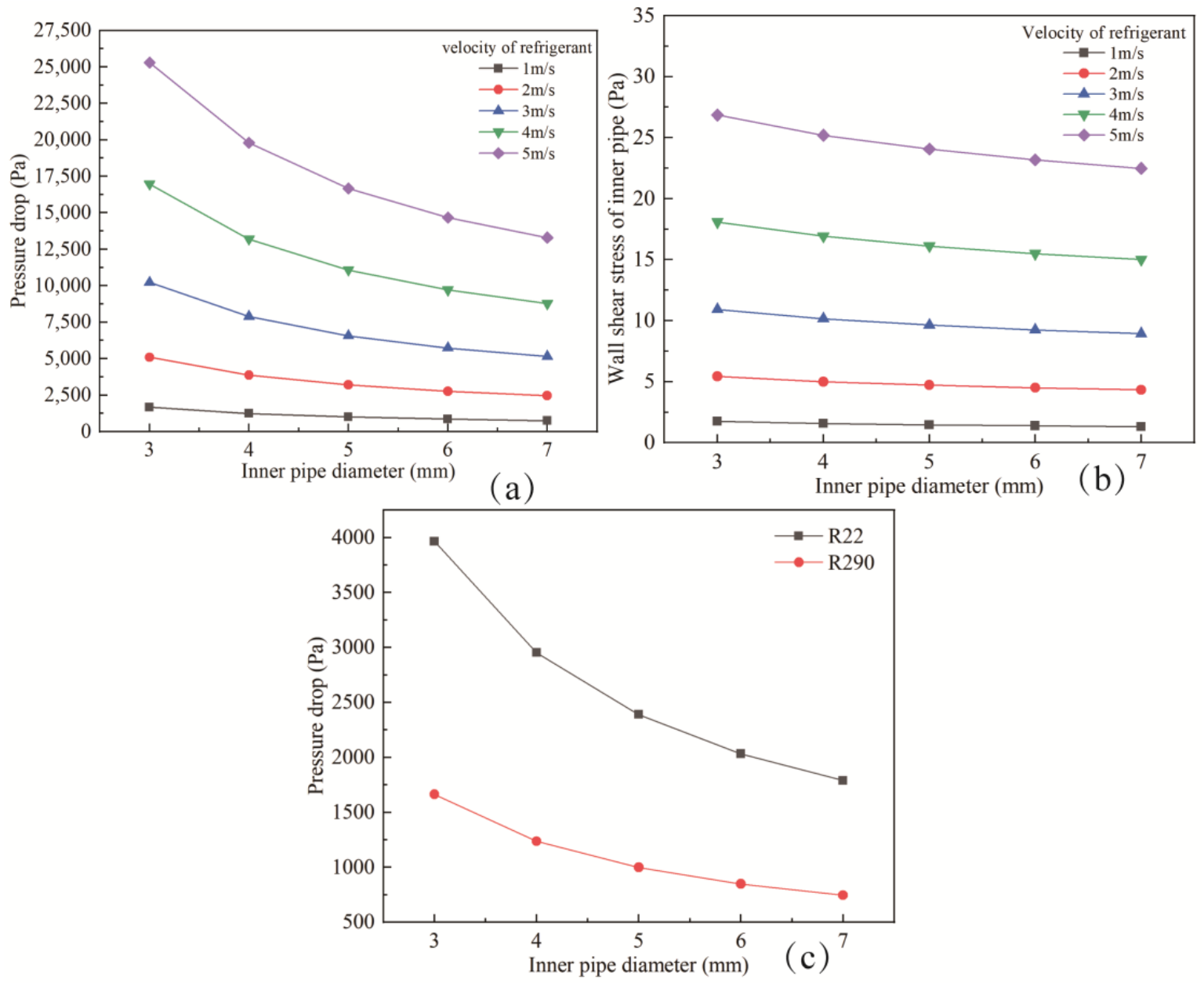

Figure 9. The impact of (a) inner pipe diameter on pressure drop, (b) wall shear stress of inner pipe and (c) pressure drop of R22 and R290 at different pipe diameters.

\subsubsection{The Impact of Refrigerant Velocity on Pressure Drop}

To research the impact of the refrigerant velocity with respect to pressure drop, the saturation temperature is kept at $283 \mathrm{~K}$ and the water velocity is kept at $5 \mathrm{~m} / \mathrm{s}$. Figure 10a shows the trend of pressure drop versus R290 velocity for five various tube diameters. The pressure drop of the internal tube grows significantly as the R290 velocity increases. As seen in Figure 10b, because of the increase of refrigerant velocity, the shear stress at the inner tube wall surface increases, and the disturbance at the inner tube wall surface increases, resulting in an increase of the friction between the refrigerant and the internal pipe wall surface. Therefore, the friction resistance pressure drop increases. The accelerated pressure drop that is generated by the different densities and velocities of the refrigerant gas-liquid phases also increases. The pressure drop increases when the refrigerant velocity increases [24]. Figure 10c reveals that the pressure drop of R290 is smaller than that of R22 at different refrigerant velocities. At the refrigerant velocity of $1 \mathrm{~m} / \mathrm{s}$, the pressure drop of $\mathrm{R} 290$ is $58.2 \%$ smaller than that of R22. At the refrigerant velocity of $5 \mathrm{~m} / \mathrm{s}$, the pressure drop of R290 is $57.3 \%$ smaller than that of R22. The pressure drop of R290 at a velocity of $2 \mathrm{~m} / \mathrm{s}$ is $33.83 \%$ higher than that of R22 at a velocity of $1 \mathrm{~m} / \mathrm{s}$. However, the pressure drop of R290 at a velocity of $3 \mathrm{~m} / \mathrm{s}$ is lower than that of R22 at a velocity of $2 \mathrm{~m} / \mathrm{s}$. The pressure drop of R290 at a velocity of $4 \mathrm{~m} / \mathrm{s}$ is lower than that of R22 at a velocity of $3 \mathrm{~m} / \mathrm{s}$. The pressure drop of R290 at a velocity of $5 \mathrm{~m} / \mathrm{s}$ is lower than that of R22 at a velocity of $4 \mathrm{~m} / \mathrm{s}$. 

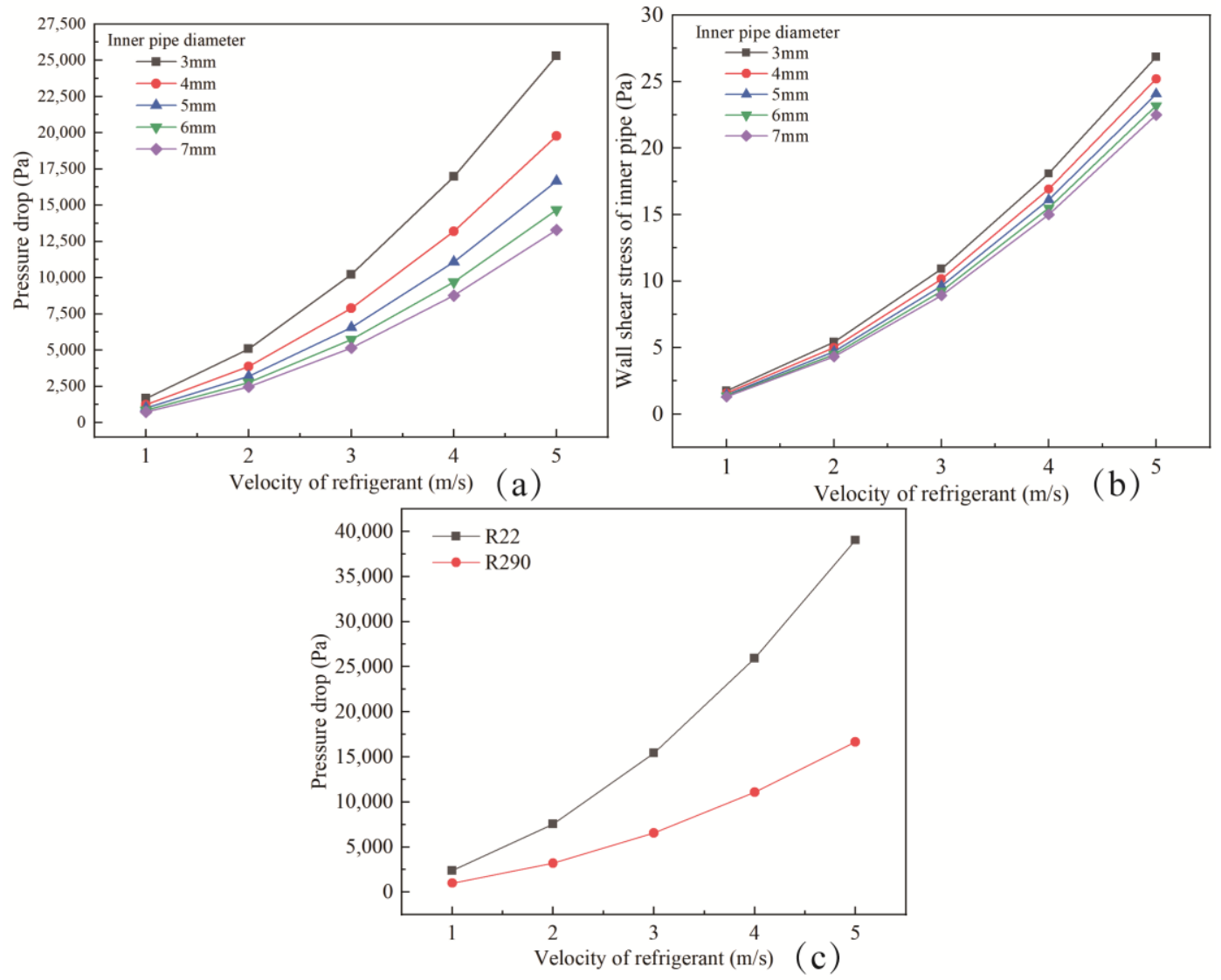

Figure 10. The impact of (a) refrigerant velocity on pressure drop, (b) wall shear stress of inner pipe and (c) pressure drop of R22 and R290 at different refrigerant velocities.

\subsubsection{The Impact of Water Velocity on Pressure Drop}

To research the impact of the water velocity with respect to pressure drop, the saturation temperature is kept at $283 \mathrm{~K}$ and the tube diameter is kept at $5 \mathrm{~mm}$. The trend of pressure drop in the internal tube versus water velocities for five different R290 velocities is presented in Figure 11a. The pressure drop in the internal pipe increases insignificantly as the water velocity increases. As shown in Figure 11b, the shear stress in the inner pipe wall increases insignificantly with the water velocity increased. This causes negligible change in the frictional resistance pressure drop. Therefore, the influence of the water velocity on the pressure drop in the internal pipe is insignificant. From Figure 11c, it is found that pressure drop of R290 is $57.3-58.3 \%$ lower than that of R22. The differential pressure drop between R290 and R22 is essentially similar at different water velocities.

\subsubsection{The Impact of Saturation Temperature on Pressure Drop}

To investigate the impact of saturation temperature with respect to pressure drop, the water velocity is kept at $5 \mathrm{~m} / \mathrm{s}$ and the tube diameter is kept at $5 \mathrm{~mm}$. The trend of pressure drop in the internal pipe with different saturation temperatures for five different R290 velocities is presented in Figure 12a. The pressure drop of the inner pipe decreases in the range of $13.8-18 \%$ as saturation temperature increases. The saturation temperature has a significant impact on the density and viscosity of the refrigerant. According to Lockhart and Martinelli [25], the density of the vapor and liquid phases of the refrigerant increases as the saturation temperature increases, resulting in a decrease of its velocity per unit volume. Consequently, the average velocity of the refrigerant vapor and liquid phases decreases, so that the accelerated pressure drop of the refrigerant decreases. At the same time, the viscosity of the refrigerant liquid phase becomes lower as the saturation temperature rises, resulting in a thinner and easier rupture of the liquid film at the internal 
pipe wall. Therefore, the surface tension of the refrigerant is lower. Therefore, the pressure drop of the frictional resistance is reduced. The pressure drop in the inner tube decreases with increasing saturation temperature [26]. Figure 12c reveals that the pressure drops of R290 is 58.2-59.7\% lower than that of R22 at different saturation temperatures. Due to the negligible impact of saturation temperature on the pressure drop, the difference in pressure drop between R290 and R22 at different saturation temperatures is not significant.
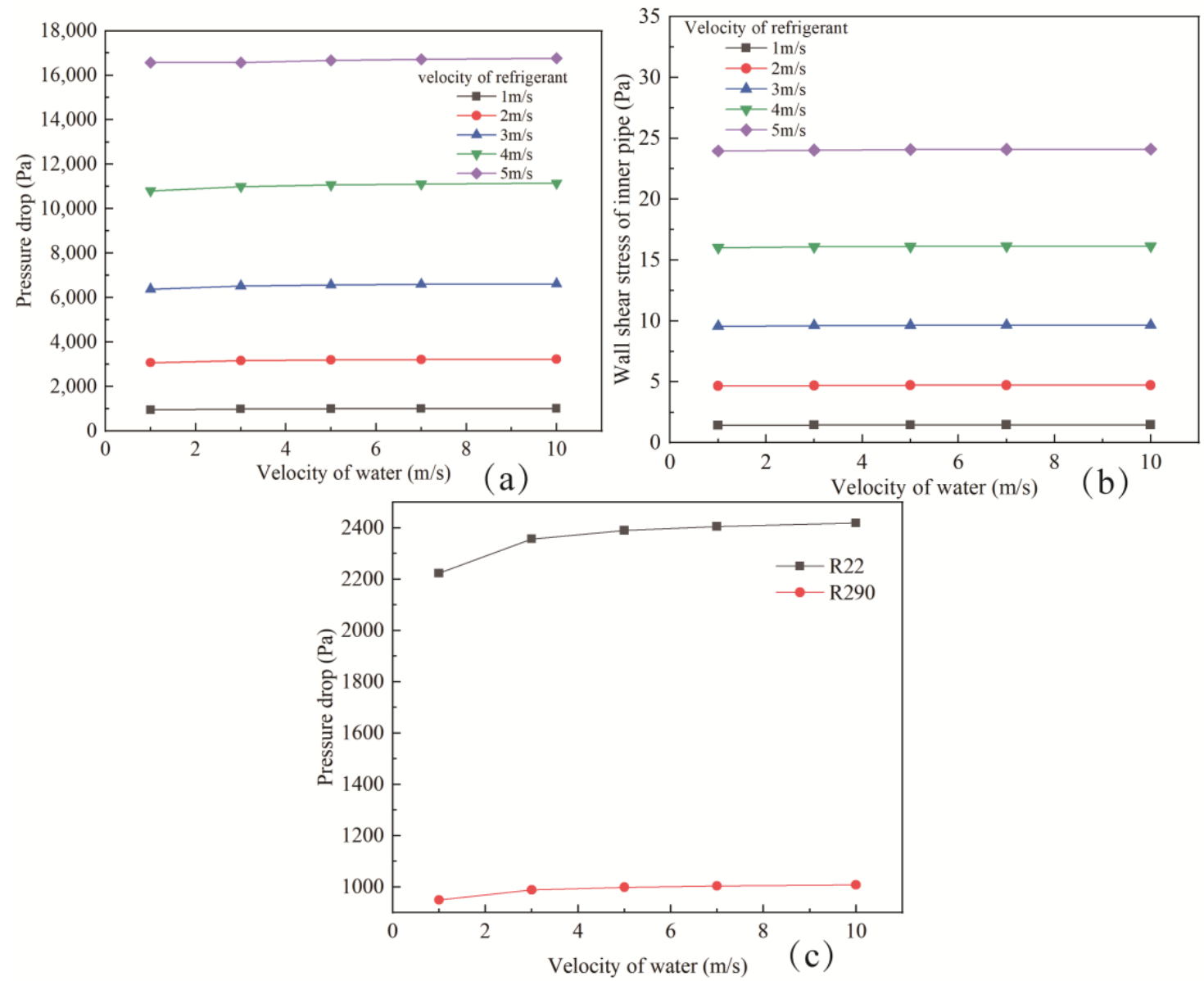

Figure 11. The impact of (a) water velocity on pressure drop, (b) wall shear stress of inner pipe and (c) pressure drop of R22 and R290 at different water velocities.

\subsection{Exergy Loss Analyses}

The exergy measures the deviation of the system from the specified state and the reference state, enabling a more comprehensive analysis of the system efficiency. Heat transfer losses and friction pressure drops generate exergy loss in the heat exchanger. Figure $13 a-d$ illustrate the variations of the exergy loss with inner tube diameter, the refrigerant velocity, the water velocity and refrigerant saturation temperature.

The trend of exergy loss with the inner tube diameter for R22 and R290 is presented in Figure 13a. The exergy loss of R290 is lower than that of R22. For small pipe diameters, the exergy loss of R290 is 4.4\% lower than that of R22, and for large pipe diameters, the exergy loss of R290 is $10.2 \%$ lower than that of R22.

The trend of the exergy loss with the refrigerant velocity for R22 and R290 is presented in Figure 13b. The exergy loss increases with increasing the refrigerant velocity. R32 has a higher exergy loss than that of R22. The exergy loss of R290 is lower than that of R22. When the refrigerant velocity is $1 \mathrm{~m} / \mathrm{s}$, the exergy loss of R290 is 7.59\% lower than that of $\mathrm{R} 22$, and when the refrigerant velocity is $5 \mathrm{~m} / \mathrm{s}$, the exergy loss of R290 is $9.31 \%$ lower than that of R22. 

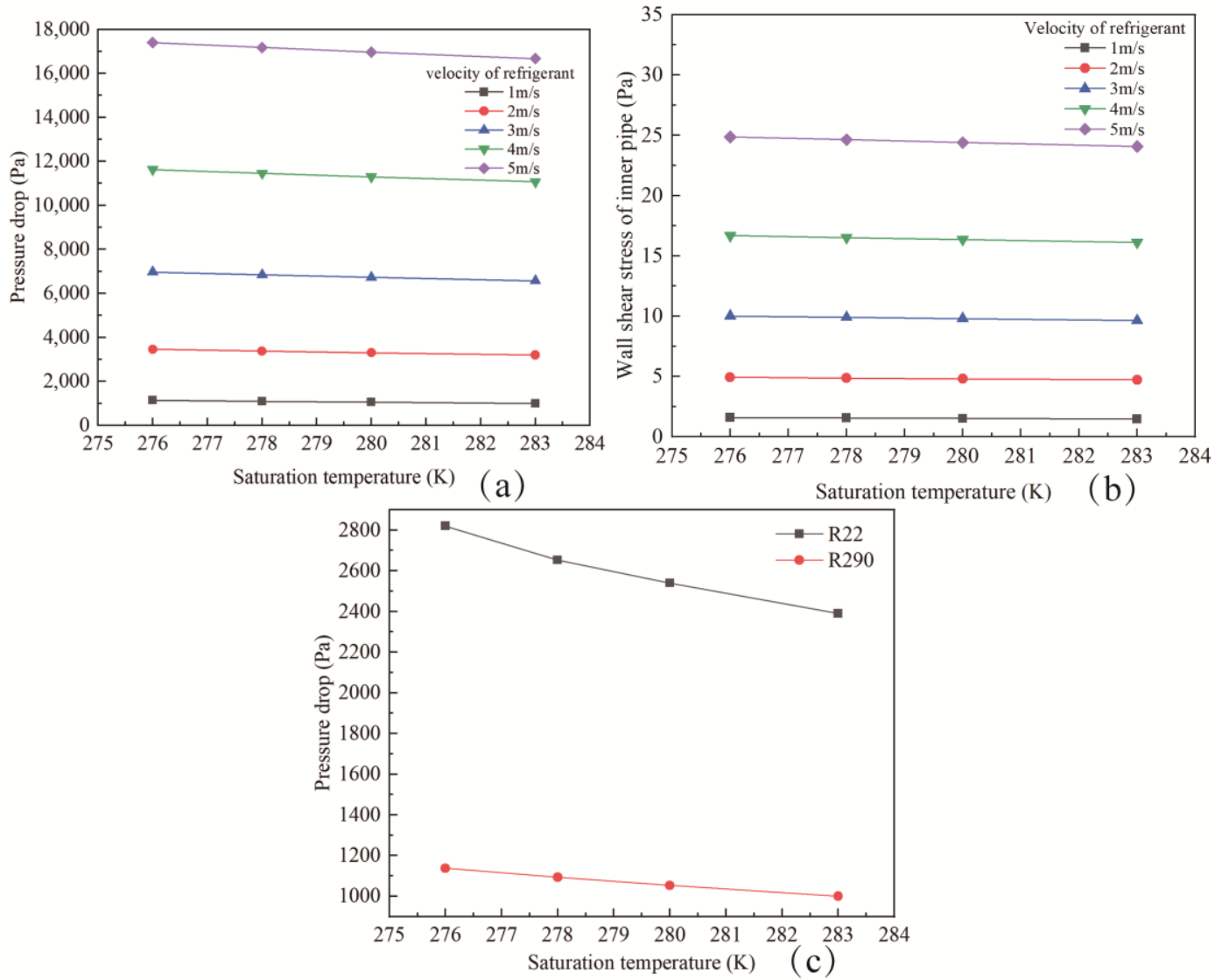

Figure 12. The impact of (a) saturation temperature on pressure drop, (b) wall shear stress of inner pipe and (c) pressure drop of R22 and R290 at different saturation temperatures.
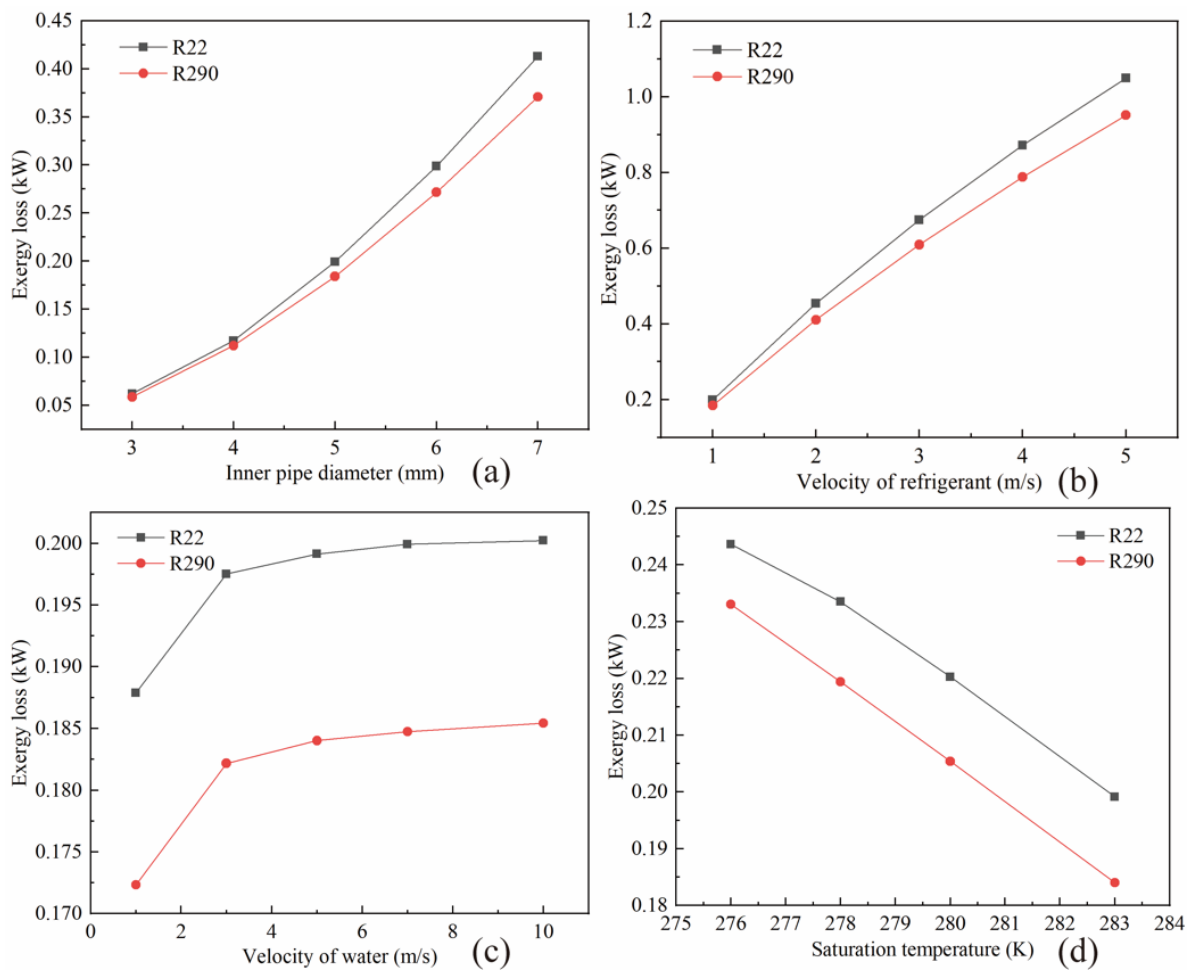

Figure 13. The impact of (a) inner pipe diameter, (b) refrigerant velocity, (c) water velocity and (d) saturation temperature on exergy loss. 
The trend of the exergy loss with the water velocity for R22 and R290 is presented in Figure 13c. The exergy loss increases with increasing water velocity. In the case of different water velocities, R290 exergy loss is lower than that of R22. At the water velocity $1 \mathrm{~m} / \mathrm{s}$, the R290 exergy loss is $12 \%$ lower than that of R22; at the water velocity of $10 \mathrm{~m} / \mathrm{s}$, the R290 exergy loss is 7.4\% lower than that of R22.

The trend of the exergy loss with saturation temperature velocity for R22 and R290 is presented in Figure 13d. The exergy loss increases as the saturation temperature increases. For different saturation temperatures, R290 exergy loss is smaller than that of R22. When the saturation temperature is $276 \mathrm{~K}$, the R290 exergy loss is $4.3 \%$ lower than that of R22, and when the saturation temperature is $283 \mathrm{~K}$, the R290 exergy loss is $7.6 \%$ lower than that of R22.

\section{Conclusions}

The numerical simulation of the 3D model is validated with Liu \& Winterton and $\mathrm{Xu}$ \& Fang's empirical equation in this article. Based on the analysis of the first law of thermodynamics and the second law of thermodynamics, the influence of the geometric, operating properties on the flow boiling of R22 and R290 in the double tube is analyzed from the numerical simulation data. The HTCs, pressure drops, and exergy losses of R22 and R290 are evaluated at the double diameter in the range of 3 to $7 \mathrm{~mm}$, the velocity between 1 and $5 \mathrm{~m} / \mathrm{s}$, the water velocity in the range of 1 and $10 \mathrm{~m} / \mathrm{s}$, and the saturation temperature in the range of 276 and $283 \mathrm{~K}$. The results are following.

(1) The maximum deviation between the numerical simulated values of HTC from the empirical equation of Liu and Winterton is $9 \%$. The maximum deviation of the numerical simulated values of pressure drop from the empirical equation of Liu and Winterton is $9.1 \%$.

(2) The pipe diameter and refrigerant velocity have more significant impact on the HTC and the pressure drop of the R290 side. While water velocity and saturation temperature have slight impact on the HTC and the pressure drop of the R290 side.

(3) With the operating conditions being the same, the exergy loss and pressure drop of R290 are $4.3-10.2 \%$ and $57.3-59.7 \%$ lower than that of R22, respectively.

(4) The HTC of R290 is 11.83-13.31\% lower than that of R22 at different conditions. But at the same refrigerant velocity, water velocity and saturation temperature, the HTC of R290 are $3.4 \%, 13.9 \%, 21.0 \%$ and $26.1 \%$ higher at the pipe diameter of $4 \mathrm{~mm}, 5 \mathrm{~mm}$, $6 \mathrm{~mm}$ and $7 \mathrm{~mm}$ than that of R22 at the pipe diameter of $3 \mathrm{~mm}$, respectively. And at the same refrigerant velocity, water velocity and saturation temperature, the HTC of R290 is larger than that of R22 when the velocity of R290 is more than that of R22. Therefore, the HTC of R290 can be improved by increasing the pipe diameter or the R290 velocity.

Author Contributions: S.Z.: Conceptualization, formal analysis, data curation, writing-original draft, review and editing. J.W.: conceptualization, funding acquisition, supervision, writing —original draft, review and editing. J.X.: conceptualization, funding acquisition, supervision, writingoriginal draft, review and editing. All authors have read and agreed to the published version of the manuscript.

Funding: This research was supported by Science and Technology Innovation Action Plan of Shanghai Science and Technology Commission (19DZ1207503), Public Service Platform Project of Shanghai Science and Technology Commission (20DZ2292200).

Acknowledgments: This research was supported by Science and Technology Innovation Action Plan of Shanghai Science and Technology Commission (19DZ1207503), Public Service Platform Project of Shanghai Science and Technology Commission (20DZ2292200).

Conflicts of Interest: The authors declare no conflict of interest 


\section{Nomenclature}

\begin{tabular}{|c|c|c|c|}
\hline C & thermal capacities & $T_{r}$ & temperature ratio \\
\hline$C p$ & specific heat at constant pressure, $(\mathrm{J} / \mathrm{kg} \mathrm{K})$ & $\mathrm{v}$ & Velocity, m/s \\
\hline $\mathrm{Cr}$ & ratio of heat capacity rate, $C_{\min } / C_{\max }$ & $W$ & Work, kW \\
\hline Di & Inner tube diameter, $\mathrm{mm}$ & $\vec{v}_{m}$ & mass-averaged velocity, $\mathrm{m} / \mathrm{s}$ \\
\hline DO & Outer tube diameter, $\mathrm{mm}$ & $\rho_{m}$ & Mixture density, $\mathrm{kg} / \mathrm{m}^{3}$ \\
\hline E & enhancement factor & $\alpha_{k}$ & Volume fraction of the $k$ th phase \\
\hline$E x$ & Total exergy, kW & $\rho_{k}$ & Density of the $k$ th phase, $\mathrm{kg} / \mathrm{m}^{3}$ \\
\hline$E x^{P H}$ & physical exergy, kW & $\vec{v}_{k}$ & The velocity of the $k$ th phase, $\mathrm{m} / \mathrm{s}$ \\
\hline$E x^{K N}$ & kinetic exergy, kW & $\mu_{m}$ & Mixed viscosity, Pa.s \\
\hline$E x^{P T}$ & potential exergy, $\mathrm{kW}$ & $\vec{v}_{d r, k}$ & Drift velocity vector of the $k$ th phase, $\mathrm{m} / \mathrm{s}$ \\
\hline$E x^{C H}$ & chemical exergy, $\mathrm{kW}$ & $\vec{v}_{d r . p}$ & Velocity of phase $\mathrm{k}$ relative to phase $\mathrm{q}, \mathrm{m} / \mathrm{s}$ \\
\hline $\begin{array}{l}\dot{E} x_{\text {loss }} \\
F\end{array}$ & $\begin{array}{l}\text { Exergy loss, } \mathrm{kW} \\
\text { suppression factor }\end{array}$ & $\begin{array}{l}\overrightarrow{v_{q p}} \\
\lambda\end{array}$ & $\begin{array}{l}\text { Relative velocity, m/s } \\
\text { Thermal conductivity, } \mathrm{W} /(\mathrm{m} \mathrm{K})\end{array}$ \\
\hline$\vec{F}$ & Bulk force & $\rho$ & Density, $\mathrm{kg} / \mathrm{m}^{3}$ \\
\hline$G_{b}$ & Turbulence kinetic energy of buoyancy & & \\
\hline$G_{k}$ & $\begin{array}{l}\text { Turbulence kinetic energy of mean } \\
\text { velocity gradients }\end{array}$ & $\varepsilon$ & heat transfer efficiency \\
\hline$H$ & Enthalpy of species, $\mathrm{kJ} / \mathrm{kg}$ & & \\
\hline $\overrightarrow{J_{j . k}}$ & Diffusive flux of species, $\mathrm{kg} /\left(\mathrm{m}^{2} \cdot \mathrm{s}\right)$ & & \\
\hline$K_{\text {eff }}$ & Effective conductivity, $\mathrm{W} / \mathrm{m} \cdot \mathrm{K}$ & Subscripts & \\
\hline$k_{t}$ & Turbulent thermal conductivity, $\mathrm{W} /(\mathrm{m} \cdot \mathrm{K})$ & $p$ & Secondary phase \\
\hline$M$ & Molecular weight, $\mathrm{kg} / \mathrm{kmol}$ & $q$ & Primary phase \\
\hline$m$ & mass flux, $\mathrm{kg} /\left(\mathrm{m}^{2} \mathrm{~s}\right)$ & $l$ & liquid \\
\hline$n$ & Number of phase & $v$ & vapour \\
\hline$P_{r}$ & Prandtl number & $c$ & Cold liquid \\
\hline$P_{f}$ & $\begin{array}{l}\text { Reduced pressure (absolute pressure/ } \\
\text { critical pressure) }\end{array}$ & $h$ & Hot liquid \\
\hline Q & Heat flux, $\mathrm{W} / \mathrm{m}^{2}$ & $i$ & inlet \\
\hline$\hat{\operatorname{Re}}$ & Reynolds number & $o$ & outlet \\
\hline$S$ & Source terms & $\max$ & maximum \\
\hline$s$ & Enthalpy, $\mathrm{kJ} /(\mathrm{kg} \cdot \mathrm{K})$ & $\min$ & minimum \\
\hline$S_{h}$ & Volumetric heat sources & & \\
\hline HTC & Heat transfer coefficient, $\mathrm{W} /\left(\mathrm{m}^{2} \cdot \mathrm{K}\right)$ & & \\
\hline $\mathrm{T}$ & Temperature, $\mathrm{K}$ & & \\
\hline
\end{tabular}

\section{References}

1. Berkah Fajara, T.K.; Restu Bagasb, P.; Ukhib, S.; Alhamidc, M.I.; Lubis, A. Energy and exergy analysis of an R410A small vapor compression system retrofitted with R290. Case Stud. Therm. Eng. 2020, 21, 100671. [CrossRef]

2. Allymehr, E.; Pardinas, A.A.; Eikevik, T.M.; Hafner, A. Characteristics of evaporation of propane (R290) in compact smooth and microfinned tubes. Appl. Therm. Eng. 2020, 181, 115880. [CrossRef]

3. Chien, N.B.; Vu, P.Q.; Choi, K.-I.; Oh, J.-T. Boiling Heat Transfer of R32, $\mathrm{CO}_{2}$ and R290 inside Horizontal Minichannel. Energy Procedia 2017, 105, 4822-4827. [CrossRef]

4. De Oliveira, J.D.; Passos, J.C.; Copetti, J.B.; van der Geld, C.W.M. Flow boiling heat transfer of propane in $1.0 \mathrm{~mm}$ tube. Exp. Therm. Fluid Sci. 2018, 96, 243-256. [CrossRef]

5. Pamitran, A.S.; Choi, K.-I.; Oh, J.-T.; Hrnjak, P. Experimental investigation on two-phase flow boiling heat transfer of five refrigerants in horizontal small tubes of 0.5, 1.5 and $3.0 \mathrm{~mm}$ inner diameters. Int. J. Heat Mass Transf. 2011, 54, 2080-2088.

6. Oh, J.-T.; Pamitran, A.S.; Choi, K.-I.; Hrnjak, P. Characteristics of two-phase flow pattern transitions and pressure drop of five refrigerants in horizontal circular small tubes. Int. J. Refrig. 2010, 33, 578-588.

7. Maqbool, M.H.; Palm, B.; Khodabandeh, R. Investigation of two phase heat transfer and pressure drop of propane in a vertical circular minichannel. Exp. Therm. Fluid Sci. 2013, 46, 120-130. [CrossRef]

8. Lillo, G.; Mastrullo, R.; Mauro, A.W.; Viscito, L. Flow boiling heat transfer, dry-out vapor quality and pressure drop of propane (R290): Experiments and assessment of predictive methods. Int. J. Heat Mass Transf. 2018, 126, 1236-1252. [CrossRef] 
9. Lee, H.S.; Bansal, P.; Kim, J.D.; Yoon, J.I. Evaporating heat transfer and pressure drop of hydrocarbon refrigerants in 9.52 and $12.70 \mathrm{~mm}$ smooth tube. Int. J. Heat Mass Transf. 2005, 48, 2351-2359. [CrossRef]

10. Mikielewicz, D.; Jakubowska, B. Prediction of flow boiling heat transfer data for R134a, R600a and R290 in minichannels. Arch. Thermodyn. 2014, 35, 97-114. [CrossRef]

11. Bejan, A. A Study of Entropy Generation in Fundamental Convective. Heat Transfer. J. Heat Transfer. 1979, 101, 718-725. [CrossRef]

12. Sheikholeslami, M.; Darzi, M.; Li, Z. Experimental investigation for entropy generation and exergy loss of nano-refrigerant condensation process. Int. J. Heat Mass Transf. 2018, 1087-1095. [CrossRef]

13. Abu-Hamdeh, N.H.; Alimoradi, A. Investigation of the effect of the finned coiled wire insert on the heat transfer intensification of circular tube: Energy and exergy analysis. Chem. Eng. Process. 2021, 160, 108245. [CrossRef]

14. Etghani, M.M.; Hosseini Baboli, S.A. Numerical investigation and optimization of heat transfer and exergy loss in shell and helical tube heat exchanger. Appl. Therm. Eng. 2017, 121, 294-301. [CrossRef]

15. Liu, Z. A general correlation for saturated and subcooled flow boiling in tubes and annuli, based on a nucleate pool boiling equation. Int. J. Heat Mass Transf. 1991, 34, 2759-2766. [CrossRef]

16. Xu, Y.; Fang, X. A new correlation of two-phase frictional pressure drop for evaporating flow in pipes. Int. J. Refrig. 2012, 35, 2039-2050. [CrossRef]

17. Dincer, I.; Sahin, A.Z. A new model for thermodynamic analysis of a drying process. Int. J. Heat Mass Transf. 2004, 47, 645-652. [CrossRef]

18. Ogulata, R.T.; Doba, F. Experiments and entropy generation minimization analysis of a cross-flow heat exchanger. Int. J. Heat Mass Transf. 1998, 41, 373-381. [CrossRef]

19. Dincer, I. The role of exergy in energy policy making. Energy Policy 2002, 30, 137-149. [CrossRef]

20. Bejan, A. Advanced Engineering Thermodynamics; John Wiley and Sons Inc: New York, NY, USA, 1988.

21. McNeil, D.A.; Raeisi, A.H.; Kew, P.A.; Hamed, R.S. Flow boiling heat-transfer in micro to macro transition flows. Int. J. Heat Mass Transf. 2013, 65, 289-307. [CrossRef]

22. He, G.; Zhou, S.; Li, D.; Cai, D.; Zou, S. Experimental study on the flow boiling heat transfer characteristics of R32 in horizontal tubes. Int. J. Heat Mass Transf. 2018, 125, 943-958. [CrossRef]

23. Choi, K.-I.; Pamitran, A.S.; Saito, K.; Oh, J.-T. Pressure drop and heat transfer during two-phase flow vaporization of propane in horizontal smooth minichannels. Int. J. Refrig. 2008, 32, 837-845. [CrossRef]

24. Jige, D.; Sagawa, K.; Inoue, N. Effect of tube diameter on boiling heat transfer and flow characteristic of refrigerant R32 in horizontal small-diameter tubes. Int. J. Refrig. 2017, 76, 206-218. [CrossRef]

25. Lockhart, R.W. Proposed correlation of data for isothermal two-phase, two- component flow in pipes. Chem. Eng. Prog. 1949, $45,39-48$.

26. Lillo, G.; Mastrullo, R.; Mauro, A.W.; Viscito, L. Flow boiling of R32 in a horizontal stainless steel tube with $6.00 \mathrm{~mm}$ ID. Experiments, assessment of correlations and comparison with refrigerant R410A. Int. J. Refrig. 2018, 97, 143-156. [CrossRef] 